\title{
Você Recebe só Para Estudar!?: A Bolsa Nossa de Cada Mês: Implicações Epistemológicas e de Sobrevivência.
}

\author{
Gustavo Matarazzo \\ Instituto Federal de São Paulo - Brasil \\ gustavo_matarazzo@yahoo.com.br
}

Se você é um pós-graduando stricto sensu, muito provavelmente, convive com algumas perguntas semelhantes à do título deste artigo. Se você ainda estuda; como faz para sobreviver; quanto tempo ainda continuará "nessa vida" e etc.. Estas questões são resultantes, frequentemente, da falta de entendimento sobre como funcionam as pósgraduações no Brasil.

De maneira breve, o Ministério da Educação estabelece dois tipos básicos de pósgraduações: lato e stricto sensu, que apresentam estruturas diametralmente distintas. Tais arquétipos titulam: especialistas, no primeiro caso, e mestres e doutores, no segundo. A pósgraduação lato sensu é a mais representativa, já que está relacionada com um maior número de instituições de ensino superior (IES) e, na maioria dos casos, tem mais apelo comercial. Caracteriza-se, sobretudo, por aulas aos finais de semana e tem como público-alvo pessoas inseridas no mercado de trabalho que têm o intuito de aperfeiçoamento em técnicas e áreas do conhecimento especificamente aplicáveis ao seu contexto de atuação. Enquanto que a pós-graduação stricto sensu se estabelece com uma carga horária maior de créditos a serem cumpridos, com aulas e período determinados para realização da pesquisa que poderá frutificar nas dissertações de mestrado ou teses de doutorado.

Ao se visualizar a estruturação da pós-graduação stricto sensu, uma das dimensões mais relevantes é a do tempo de dedicação necessário para sua realização. Nesse contexto de dedicação surge uma das figuras mais controversas desse tipo de pós-graduação: os bolsistas. Minha hipótese argumentativa é de que essa figura seja um dos elementos estruturantes da performance desse tipo de curso. Já que nas relações desenvolvidas a partir dos bolsistas é que se estabelece a conjuntura entre tempo necessário de dedicação ao curso e as formas de trabalho desenvolvidas. Quero dizer que é somente por meio de bolsas de 
estudos que os estudantes podem trabalhar ${ }^{1}$ nos grupos de pesquisas e se dedicar de maneira exclusiva aos cursos de pós-graduação.

Mas quem são os bolsistas?

De maneira geral, o bolsista é caracterizado pelo recebimento de um valor pecuniário mensal ( $\mathrm{R} \$ 1.500,00$, mestrando, e $\mathrm{R} \$ 2.200,00$, doutorando) para que se dediquem "exclusivamente" ao curso. Chamo atenção ao "exclusivamente" porque o próprio termo assume significações contextualizadas, sobretudo, com relação às normas dos diferentes programas de pós-graduação e áreas de conhecimento (diferenciação bastante evidente entre as hard e soft sciences). Neste sentido, permitir que os estudantes realizem outras tarefas (com o acúmulo de bolsa, por exemplo) depende do que é entendido como "exclusividade".

Nessa perspectiva, parece-me importante pensar a dimensão político-epistemológica que configura os interesses de pesquisa e, consequentemente, as relações produzidas entre mão de obra e recursos disponíveis para certas temáticas. Quero dizer que, a aplicabilidade do conhecimento ${ }^{2}$ produzido é uma determinante para a disponibilização de recursos para bolsas de estudo. Considera-se, por exemplo, o subsídio de empresas/indústrias a projetos de interesse em determinadas áreas do conhecimento.

A figura dos bolsistas acompanhou a expansão, de maneira geral, das pós-graduações em quase que todas áreas de conhecimento no Brasil nos últimos anos (em destaque nos governos dos presidentes Luiz Inácio Lula da Silva e Dilma Rousseff). Embora estejam presentes em todas as universidades com cursos de pós-graduação stricto sensu, as instituições públicas, em especial, se tornaram o local de maior concentração deste "personagem". Tal movimento na pós-graduação - que, consequentemente, passou a formar mais mestres e doutores - coaduna com o conjunto de regulamentações (vigentes atualmente) que avaliam de maneira positiva as IES com mestres e doutores em seus quadros docentes 3 ; o que implica na realização de concursos públicos que privilegiam esse perfil de profissional.

Para se ter uma ideia sobre a representatividade dos bolsistas de pós-graduação stricto sensu, no presente ano (2017), há 76.914 bolsistas no programa de Demanda Social4

\footnotetext{
${ }^{1}$ Refiro-me, aqui, à relação de trabalho, não trabalhista (ou vínculo empregatício).

2 Uma controvérsia que ilustra a avaliação a respeito da "importância” do conhecimento produzido está relacionada ao Programa Ciências Sem Fronteiras, que privilegiou determinadas áreas de conhecimento, em detrimento a outras.

3 Sobretudo na avaliação e ranqueamento dos cursos de graduação e pós-graduação.

4 Tipo de bolsa instituída pela CAPES com maior número de beneficiários para estudantes brasileiros de pósgraduação em instituições nacionais.
} 
da Coordenação de Aperfeiçoamento de Pessoal de Nível Superior (CAPES)5, programa em que é oferecido o maior número de bolsas para mestrado e doutorado no Brasil. Enquanto que o Conselho Nacional de Desenvolvimento Científico e Tecnológico (CNPq), segundo dados de 2015, ofereceu 162.349 bolsas de mestrado e doutorado6 ${ }^{6}$. Tais dados, auxiliam-nos, a embasar o argumento de que é, cada vez mais, necessário refletir sobre as condições que o "viver de bolsa" impõem aos estudantes.

Tal reflexão se torna ainda mais urgente ao se visualizar as muitas doenças paulatinamente instauradas na academia, em especial, nas pós-graduações. No dia 27 de outubro de 2017, no caderno ciência do jornal Folha de São Paulo, o jornalista Fernando Tadeu Moraes publicou a reportagem intitulada: "Suicídio de doutorando na USP levanta questões sobre saúde mental na pós". A reportagem sustenta alguns fatores como agravantes ao quadro de saúde mental dos estudantes, a saber: prazos apertados, pouco dinheiro, pressão para publicação, carga de trabalho excessiva, cobranças e solidão.

Os relatos de casos traumáticos e adoecimentos nas pós-graduações retratam um cenário que parece sofrer de uma crescente degeneração. Alguns esforços têm sido feitos para que essas situações se tornem públicas e objetos de problematização. Este artigo é a materialização de um esforço iniciado em um painel paralelo do Encontro da Associação Nacional de Pós-Graduação e Pesquisa em Administração (EnANPAD) de 2016, intitulado: “Os desafios dos Jovens Pesquisadores no Campo dos Estudos Organizacionais no Brasil”. Neste painel, coordenado pelo professor Rafael Alcadipani (FGV-EAESP), compusemos a mesa: eu, Josiane Oliveira (professora na Universidade Estadual de Maringá), Juliana Teixeira (professora na Universidade Federal de São João del-Rei), Marina Dantas (professora na Universidade de Fortaleza) e Wescley Xavier (professor na Universidade Federal de Viçosa). Era eu, naquele momento, o único doutorando, e pude externalizar algumas preocupações, que fizeram eco na sessão e nos momentos de conversas do evento. Em resumo, aquela representava, para mim, uma ocasião bastante oportuna, já que se tratava do último fôlego para finalizar a tese, eu não contava com perspectivas de empregabilidade após a defesa e restavam-me poucos meses de bolsas de estudos. Enfim, ao tempo em que iniciava a vida de doutor, também acostumava com a situação de desempregado.

5 O Sistema de Disseminação de Informações (SDI) congrega diversos dados, o acesso se dá pelo seguinte endereço: http://sdi.capes.gov.br/index.php/informacoes-relevantes.html

${ }^{6}$ Dados coletados em: cnpq.br/dados_abertos/ 
A minha trajetória é comum à de muitos estudantes que parecem constituir uma nova geração de pós-graduandos, aqueles que "emendaram” as fases de formação, e saíram das universidades, como doutores. Esse tipo de formação, sem espaços de tempo entre os cursos, forma acadêmicos com pouca experiência profissional e relações de trabalho anteriores, ao mesmo tempo, que com uma vasta experiência de viver de bolsa e dedicação exclusiva às atividades da pós-graduação, participação de grupos de pesquisas, organizações de eventos, realização de projetos pesquisas, estágios docências e etc. A minha formação na pósgraduação - mestrado e doutorado - aconteceu em um programa conceituado com a nota 4 da CAPES, o que quer dizer muita coisa já que significa estar fora do eixo dos programas de pós-graduações com pontuações altas (6 e 7), ao mesmo tempo em que é o reflexo da realidade da maioria dos programas.

A minha experiência pessoal quanto à escolha da carreira é semelhante à de muitas outras pessoas, assim sendo, pretendo articulá-la enquanto um guia para o presente texto. Mas, para além da "contação" da minha história, tenho a presunção de que este meu relato contribua para a problematização e desnaturalização desta realidade; a experiência pessoal é aqui colocada enquanto um operador analítico de investigação da realidade.

Nesse sentido, decidi priorizar duas facetas do fenômeno "ser bolsista": a epistemológica e a material. Acredito que essas duas dimensões são capazes de auxiliar-me na condução da argumentação, porque são horizontais às pós-graduações e constituidoras da figura do bolsista.

Inicio pelos aspectos epistemológicos7, reconhecendo a dimensão política inerente a esta discussão. Mesmo o pesquisador que carrega a pretensão da neutralidade axiológica sustentada por uma orientação epistemológica positivista, está, em todo o processo de pesquisa, envolvido em um processo, tipicamente, político. Ainda que a moda seja a de desconfigurar esse termo, sabemos que a escolha de um tema não tem a ver, somente, com suas ideias e/ou vontades, mas com interesses pessoais e institucionais. Trata-se, portanto, de uma equação complexa com inúmeras variáveis.

O pós-graduando, ordinariamente, se encontra em uma posição na qual o financiamento (bolsa) apresenta um peso importante para a continuidade de seus estudos ou grau de dedicação ao curso. Convivi, em minha trajetória, com colegas detentores de outras fontes de renda, ou já inseridos na docência, em cargos públicos, o que lhes garantia

\footnotetext{
7 Entendidos para além da produção dos documentos escritos e dos títulos acadêmicos enquanto produtos, mas como uma experiência mais complexa relacionada aos aspectos (trans)formadores das dimensões cognitivas, psicológicas e sociais dos indivíduos.
} 
estabilidade, e pude perceber que por essas circunstâncias emergiam algumas diferenças. Minha impressão é de que essas pessoas estavam em uma posição de menor vulnerabilidade quanto à escolha do que iriam estudar o que implicaria em maior grau de envolvimento e satisfação pessoal quanto à temática (mesmo que não houvesse uma total liberdade de escolha, o que também é compreensível). Já com os bolsistas, esta decisão atrelava-se ao exame da possibilidade de financiamento (bolsa), fosse por meio da temática ou da influência do orientador no campo, com, por exemplo, a coordenação de projetos.

Esse cenário ainda pode ser refletido a partir da visão de que, quem conta com "certa" estabilidade financeira, tem, possivelmente, maior facilidade para a interrupção/paralisação da pós-graduação, troca de temática ou de orientação. Situações pouco (ou se quer) consideradas por bolsistas conformados, já que, a desistência da pós-graduação, provavelmente, os colocará, de imediato, em situação de desemprego. Os bolsistas estão, neste sentido, em uma situação diferenciada no que tange aos acordos sobre a decisão do seu tema de pesquisa. Há um continuum que se estabelece entre a liberdade do estudante e a rígida preensão - por vezes, imobilidade - às condicionantes institucionais, em parte, regidas, preponderantemente, pelos orientadores.

Um outro ponto que se estabelece, a partir dos posicionamentos epistemológicos assumidos no trajeto da pós-graduação, está relacionado à busca de pertencimento, que está presente em questões como: "Quero ser (re)conhecido pelo quê? A que campo quero pertencer? Que tipo de trabalho quero fazer? Em quais eventos quero estar presente?”. De modo geral, há uma necessidade de presença, aparecer, colocar-se à academia. Tal fato está, intimamente, ligado à perspectiva de que o estudante passa a carregar uma espécie de legado do(s) seu(s) orientador(es), que contribui para a construção de uma marca na sua produção intelectual que está a começar. Ao publicar, em revistas científicas, em coautoria com seus orientadores, os estudantes se constituem, na maioria das vezes, como as possíveis vozes de continuidade e avanço em certos campos de estudos.

A questão de fazer-se presente tem custos, tanto materiais quanto psicológicos. Cada vez mais, pós-graduandos (incluindo bolsistas) precisam arcar com os custos materiais envolvidos nas pesquisas, especialmente, em momentos de crise com cortes orçamentários, como a que vivemos. O valor da bolsa passa, então, a bancar, além dos custos de sustento, os de inscrições, viagens, estadas, aquisição de livros, e etc.

Nesse sentido, há um remarque necessário a se fazer em relação ao Encontro da ANPAD, um dos mais importantes eventos da área; considerado como "passagem 
obrigatória" aos pós-graduandos, pois, afinal de contas, dispõe do "baile das referências"”", que os inscreve no campo. O encontro apresenta taxas de inscrição de, em média, R\$ 1.200,o0, com descontos para estudantes que a podem reduzí-la pela metade. Este valor tem sido destinado restritamente à inscrição, sem abarcar estada ou alimentação, como já foi no passado. Assim, na maioria das vezes, os bolsistas realizam malabarismos orçamentários para fazerem-se presentes. Quanto aos professores de universidades públicas, o evento torna-se "auto-financiado" pelo Estado, já que os custos totais são, normalmente, ressarcidos por meio de solicitação do auxílio a eventos das próprias instituições.

Já os custos psicológicos estão associados às experiências de exposição aos pares e de submissão de seus trabalhos ao escrutínio público. Além disso, tratam-se de processos de aprendizagem que se referem às capacidades de comunicação de uma temática específica e complexa em um tempo (geralmente curto) controlado; além do preparo para responder prontamente questionamentos e críticas sobre seu estudo e exposição. Aqui o remarque se dá a certos professores sêniores a quem falta a consciência de se tratar de um processo de formação e que massacram trabalhos e pessoas com o subterfúgio de que faz "parte da trajetória acadêmica”, como um meio pedagógico. Postura esta, que parece, estar mais atrelada ao narcisismo com finalidade de auto-promoção. A situação fica ainda mais perigosa e vexatória, quando os estudantes são utilizados como alvos para ataques raivosos entre orientadores, ou seja, reflexos das disputas de campos científicos, autores e espaços.

Dito isso, passarei a um dos aspectos mais controversos e discutidos por diferentes autores: a produção científica - na qual os bolsistas também são peças chaves. Parece-me que há um consenso sobre a produção científica enquanto elemento fundamental no ranqueamento de pessoas e instituições, que a tornou um tipo de "mal necessário".

Uma das análises a esse respeito, que ganhou notoriedade para além dos meios acadêmicos, foi a do cientista Fernando Reinach (2013) - professor titular da Universidade de São Paulo e membro da Academia Brasileira de Ciências -, que, em sua coluna no jornal "O Estado de São Paulo", discutiu aquilo que vem sendo intitulado como "Salami Science": prática de fatiar uma única descoberta com o intuito de obter um maior número possível de artigos. No artigo "Darwin e a prática "salami science"”, o professor afirma que essa prática estaria associada à obsessão, baseada em uma perspectiva quantitativista, por um método capaz de avaliar a produção acadêmica. Processo, este, que desencadearia uma espécie de

8 Festa realizada pelo evento após jantar de confraternização, na qual se encontram algumas das pessoas que são consideradas referências da área. 
darwinismo científico, no qual a permanência do pesquisador no campo dependeria da sua adaptação.

No campo da Administração sofremos os reflexos do mesmo fenômeno, na busca incessante por publicações que tenham algum impacto, em termos anglicistas, como nosso campo prefere, nos top journals; o que nos leva a um cenário obsessivo e patológico, que reduz formações à pós-graduações e, consequentemente, as pessoas a números e planilhas.

É bastante evidente a presença de práticas organizativas que visam cooperações produtivistas, ou "troca de favores": "você coloca o meu nome, que eu coloco o teu". Durante a pós-graduação ouvi diversos relatos nesse sentido, não desconsiderando a idiossincrasia dos campos de estudo no que tange a estas práticas. No entanto, de maneira geral, é comum orientadores obrigarem seus alunos (ainda que de forma tácita/velada) - em especial, os bolsistas - a colocarem seus nomes nos trabalhos. Deixei de escrever artigos, frutos de disciplinas, com certos colegas, por seus orientadores exigirem a "coautoria”, mesmo que nada fizessem para a construção dos trabalhos. Tal fato, segundo meus colegas, era fator sine qua non, para que esses professores os orientassem. Parece-me que em diversos casos, a produção dos orientadores ocorre às custas do corpo de bolsistas sob sua orientação.

Há, ainda, que se considerar o aspecto temporal das produções científicas. As pesquisas de bases qualitativas, habitualmente, levam mais tempo para serem realizadas. As etapas de coletas de dados, categorizações e sistematizações necessitam de inter-relações longínquas entre empiria, teoria e metodologia. Enquanto pano de fundo, essa relação temporal faz com que seja valioso criar uma espécie de estratégia de publicação (o que pode ser explicado pelo darwinismo científico, do professor Reinach (2013)) mecanismo que garanta publicações periódicas e atenda aos critérios de pontuação da CAPES, levando em conta os tempos de pesquisa, preparação dos artigos e avaliações das revistas. Há professores que trabalham nesta perspectiva acelerando (ou retardando) suas produções conforme os tempos de análise de credenciamento dos programas de pós-graduações.

Enquanto essas publicações se sustentam como eixo central para avaliação dos professores, se transformam em necessidade nos currículos dos bolsistas. Já que, ao saírem das pós-graduações, a maioria dos estudantes submeter-se-á aos concursos públicos. Nesses casos, as publicações são determinantes para a constituição de um bom currículo Lattes, ao se pensar os critérios adotados por esses certames. Essa situação fica ainda mais evidente nos programas em que a dedicação exclusiva impede que os acadêmicos façam outras atividades pontuáveis, como lecionar em outras instituições. Nestes casos, os bolsistas veem 
na publicação a (única) possibilidade de construir currículos para o ingresso no mercado de trabalho.

Passarei para uma discussão mais centrada na situação material do bolsista, não que ela não tenha estado presente anteriormente, já que a centralidade do "ser bolsista” está na perspectiva financeira. No entanto, há algumas preocupações que necessitam ser colocadas em discussão. O bolsista, na maioria das vezes, estabelece vínculos relacionais duráveis durante seu trabalho de pesquisa. A dedicação exclusiva ao programa de pós-graduação resulta, por exemplo, na constituição de amizades com o corpo administrativo, que muitas vezes, exerce a escuta e o aconselhamento, em verdadeiras sessões terapêuticas sobre os problemas e indignações que afetam os estudantes. Além de o bolsista estender suas relações pessoais para a universidade, o tempo de permanência na instituição torna o espaço físico do programa, ou do grupo de pesquisa a que pertence, a extensão de sua residência. São comuns os espaços nas prateleiras e armários que servem para guardar os objetos pessoais, além de estudantes que dormem ou passam os finais de semana nos grupos de pesquisa, situações mais comuns aos pesquisadores que realizam experimentos.

O trabalho do bolsista quase sempre ultrapassa as oito horas diárias - o que costuma ser motivo de orgulho, tanto dos próprios estudantes como de seus orientadores. Esse fato é alusivo, ao meu ver, a algo que denominarei de unidimensionalização: trata-se de um fenômeno de cooptação, no qual a dimensão do trabalho incorpora outros espaços e aspectos do mundo da vida, como os individuais e sociais. Em conversas com pesquisadores das ciências médicas, escutei que gostavam de que seus bolsistas "vivessem" em nos laboratórios, em especial, aos finais de semana, e que isso era o reflexo do trabalho árduo e do ambiente competitivo em suas áreas de estudos. No entanto, embora estejamos falando de uma situação que ultrapassa o trabalho, já que se congrega com a formação dos indivíduos, esse tipo de prática está intimamente ligada a altas cargas de estresse, crises de ansiedade e episódios de burnout. Defendo, neste sentido, que se pense em medidas que atenuem estes efeitos, como: permitir que os bolsistas realmente gozem das férias, sem precisar responder a e-mails; estabelecer horários de trabalho que os possibilitem ter espaço para a vida pessoal e o lazer; construir/preservar espaços de conversas, para que tenham suas inquietações compartilhadas com pessoas nas mesmas situações; considerar o trabalho aos finais de semana exceção, não regra.

Por outro lado, é interessante reconhecer que esse tipo de relação pode ser "utilizada" pelos orientandos como uma das formas de desenvolver trabalhos medíocres, que serão 
aprovados devido à "necessidade” (velada) de que os alunos "se formem”. Há casos de doutorandos com bolsa que não conseguiram terminar os cursos e não tiveram que prestar quaisquer informações sobre o dinheiro investido nos anos de sua formação. Em resumo, esse limbo permite “comportamentos questionáveis” por parte dos diversos atores.

A situação de bolsista também pode assumir uma perspectiva de continuísmo, já que ter uma bolsa por dois ou quatro anos - em momentos de mais estabilidade na educação pode se constituir em uma boa oportunidade frente ao mercado de trabalho, especialmente para estudantes que realizaram iniciações científicas ao invés de estágios em organizações. Para essas pessoas, a carreira acadêmica parece ser a possibilidade mais segura. Assim sendo, a pessoa ao sair da graduação enxerga a bolsa de mestrado como uma oportunidade de geração de renda, e, então, ao terminar o mestrado continua no doutorado com essa mesma visão. A bolsa não é vista como uma forma de garantia de certo nível de renda para a realização de um curso de pós-graduação, mas como uma possibilidade de salário por 2, 4 ou 6 anos. Nesse sentido, questões de vocação para a pesquisa e docência não são tomadas como as mais importantes. Por exemplo, o salário base de um administrador recém-formado em Florianópolis é próximo de 1500 reais, o que o equipara a uma bolsa de mestrado.

Em termos de gastos que a bolsa serviria para arcar é evidente a sua insuficiência, pois elas também são empregadas nos custos das próprias atividades acadêmicas. Computadores, revisões, deslocamentos para a pesquisa, entre uma infinidade de outras tarefas, são exemplos desses custos. Em matéria veiculada pela revista Galileu, no dia 25 de julho de 2016, de autoria de Guilherme Brendler, intitulada "A ciência no Brasil é bancada pelos pais”, o jornalista afirma que as bolsas de estudantes de mestrado e doutorado pagam menos de que o mínimo necessário para que os pesquisadores se mantenham e a solução é pedir ajuda à família ou "fazer bicos" para quitar as contas. Os estudantes se constituem como parte de uma mão de obra "barata" no mercado, que pode ser adquirida por outras instituições. Este é o caso da docência em outras faculdades ou cursos de pós-graduação lato sensu, quando a legislação e as regras da exclusividade não impedem. É fundamental que discutamos sobre um arcabouço legal garantidor da correção dessas bolsas no cenário econômico, constituindo-se uma política de Estado que não dependa dos interesses momentâneos dos ministérios ou do governo federal.

Um ponto curioso sobre a questão da bolsa é com relação às Ciências Sociais Aplicadas e as evidências sobre as potencialidades dos desenvolvimentos científicos. Para quem trabalha na área, como eu, não resta dúvidas da importância das pesquisas e, 
sobretudo, da pluralidade com relação às lentes para discutir e refletir sobre os diversos fenômenos. No entanto, para um público mais leigo, estamos distantes das figuras dos cientistas, e nosso trabalho não merece o mesmo incentivo do que o dos que estão inseridos nas hard sciences. Um pouco desse pensamento foi refletido na própria política do Programa Ciências Sem Fronteiras, que priorizou alunos da graduação em determinadas áreas aos da pós-graduação nas Ciências Sociais e Sociais Aplicadas. Dessa forma, é importante que pensemos em estratégias políticas de garantia de financiamentos para a nossa área de maneira geral.

Em vias de conclusão, acredito que temos que nos questionar e criar espaços para discutirmos nossas práticas acadêmicas. A situação dos bolsistas, em especial, carece de debate, mesmo que constitua a realidade da maioria dos estudantes de pós-graduações em escolas públicas, locais em que se desenvolvem o maior número de pesquisas científicas no Brasil.

Para que esta exposição argumentativa não se equipare a uma metralhadora armada contra tudo e todos, busquei sugerir, humildemente, algumas considerações que possam resultar em efeitos concretos nas realidades dos futuros bolsistas, que a todo momento ingressam na pós-graduação. Primeiro, é essencial que tornemos mais claras as relações entre orientadores e bolsistas, mesmo que haja toda uma regulamentação formalizada pelas instituições de fomento e pelos programas de pós-graduação. É necessário que as práticas sejam problematizadas e que não naturalizemos disfunções e distorções, com os subterfúgios das necessidades de adaptarmos ao meio científico e às imposições reguladoras. O segundo ponto (salientado na discussão do EnANPAD pela professora Maria José Tonelli) é de que o mestrado e o doutorado sejam mais específicos no que tange às formações do professor, no primeiro, e do pesquisador, no segundo; para que assim surjam oportunidades como, por exemplo, o trabalho como professor assistentes e em projetos de pesquisas. E, por fim, que os congressos - em especial os da ANPAD - sejam sensíveis às realidades desses jovens pesquisadores e dos recém doutores ainda sem colocação (situação em que o congresso duplica de valor em relação aos estudantes).

Antes de finalizar, gostaria de dedicar um parágrafo a respeito do assédio às mulheres, os quais se expressam, volta e meia, em eventos científicos, mas que são constituídos, paulatinamente, no cotidiano. Penso que seja necessário espaços de discussão sobre a temática e que possamos desnaturalizar hábitos tão sórdidos que são vistos como comuns ou resultados de uns copos a mais. Sei que há diversas intenções e ações já em curso 
para tornar público e discutível esses comportamentos. Nesse sentido, acredito que devemos trabalhar com a abertura de espaços para que esses relatos e estudos emerjam. Decido, nesse sentido, abster-me de trabalhar em profundidade, pois não realizei nenhum estudo para tal, no entanto, sem desconsiderar a urgência, importância e complexidade da temática.

Destaco que esse texto foi fruto do convite do editor desta revista, professor Marcelo Bispo, ao qual agradeço imensamente. E como tem ocorrido nas conversas nos bastidores dos eventos, urge, sobretudo, a necessidade da humanização das relações acadêmicas. Não podemos mais permitir as diversas práticas abusivas que ocorrem nessas relações e nas quais os bolsistas são as figuras mais vulneráveis. Penso que seja fundamental um posicionamento de mulheres que convivem com diversos assédios nos cotidianos e eventos acadêmicos. No mais, temos o dever de desnaturalizar as práticas perversas deste ambiente, que se tornou doentio, a fim de recuperar o seu caráter inerentemente pedagógico e científico. 